\title{
Juvenile-adult tree associations in a continental Mediterranean ecosystem: no evidence for sustained and general facilitation at increased aridity
}

\author{
Elena Granda, Adrián Escudero, Marcelino de la Cruz \& Fernando Valladares
}

\section{Keywords}

Juniperus thurifera; Pinus nigra; Quercus

faginea; Quercus ilex; Regeneration; Spatial patterns; Stress-gradient hypothesis; Water availability

\section{Nomenclature}

Castroviejo, S. (1986-2011)

\author{
Abbreviations \\ HWA plots = high water availability plots; LWA \\ plots = low water availability plots; SGH = \\ stress-gradient hypothesis \\ Received 3 November 2010 \\ Accepted 9 August 2011 \\ Co-ordinating Editor: Valerio Pillar \\ Granda, E. (corresponding author, \\ elena.granda@ccma.csic.es) \& Valladares, F. \\ (valladares@ccma.csic.es): Laboratorio \\ Internacional de Cambio Global (LINC-Global), \\ Museo Nacional de Ciencias Naturales MNCN, \\ CSIC, Serrano 115 dpdo, 28006, Madrid, \\ Spain \\ Escudero, A. (adrian.escudero@urjc.es) \& \\ Valladares, F.: Departamento de Biología y \\ Geología, ESCET, Universidad Rey Juan Carlos, \\ Tulipán 5/n, 28933, Móstoles, Spain \\ de la Cruz, M. (marcelino.delacruz@upm.es) \\ Departamento de Biología Vegetal, E.U.I.T. \\ Agrícola, Universidad Politécnica de Madrid, \\ 28040, Madrid, Spain
}

\begin{abstract}
Question: How do tree species identity, microhabitat and water availability affect inter- and intra-specific interactions between juvenile and adult woody plants?
\end{abstract}

Location: Continental Mediterranean forests in Alto Tajo Natural Park, Guadalajara, Spain.

Methods: A total of 2066 juveniles and adults of four co-occurring tree species were mapped in 17 plots. The frequency of juveniles at different microhabitats and water availability levels was analysed using log-linear models. We used nearest-neighbour contingency table analysis of spatial segregation and J-functions to describe the spatial patterns.

Results: We found a complex spatial pattern that varied according to species identity and microhabitat. Recruitment was more frequent in gaps for Quercus ilex, while the other three species recruited preferentially under shrubs or trees depending on the water availability level. Juveniles were not spatially associated to conspecific adults, experiencing segregation from them in many cases. Spatial associations, both positive and negative, were more common at higher water availability levels.

Conclusions: Our results do not agree with expectations from the stressgradient hypothesis, suggesting that positive interactions do not increase in importance with increasing aridity in the study ecosystem. Regeneration patterns are species-specific and depend on microhabitat characteristics and dispersal strategies. In general, juveniles do not look for conspecific adult protection. This work contributes to the understanding of species co-existence, proving the importance of considering a multispecies approach at several plots to overcome limitations of simple pair-wise comparisons in a limited number of sites.

\section{Introduction}

Spatial patterns of adult plants in Mediterranean ecosystems are the result of seed dispersal and complex environmental filters occurring at the earliest life stages (Tirado $\delta$ Pugnaire 2003), which are later either mitigated or exacerbated by plant-plant interactions (Kunstler et al. 2007). It is well known that the main limiting factor during plant establishment in these ecosystems is drought, coupled with heat and intense irradiance. Water shortage represents the most important factor for juvenile mortality and constitutes a key environmental filter structuring community assemblages and dynamics in Mediterranean ecosystems (Espelta et al. 1995; Gómez-Aparicio et al. 2004; SánchezGómez et al. 2006). High irradiance further reduces soil water availability, increases evaporative demand and causes photoinhibition, significantly decreasing carbon assimilation (Valladares et al. 2005). In mesic conditions, light limitations are more important than moisture limitations, so plants tend to recruit in gaps (Holmgren et al. 
1997), with intermediate situations showing complex patterns influenced by both water and light availability (Kunstler et al. 2006; Valladares et al. 2008). Increasing evidence shows that the filtering effect of these abiotic factors affects the sign and intensity of biotic interactions. The 'stress-gradient hypothesis' proposes that facilitation increases under stressful conditions (Bertness \& Callaway 1994), but recent refinements (Michalet et al. 2006; Maestre et al. 2009) suggest that positive interactions may diminish at extreme stress conditions. Positive and negative interactions typically occur simultaneously due to shifts along ontogeny and to the high number of interacting factors and species in a community, the balance between them being critical for community organization (Callaway \& Walker 1997; Miriti 2006). Yet, these biotic interactions and the individual response to the numerous filtering factors vary depending on species identity, intensity of the biotic or abiotic stress, the physiological requirements of the species and a number of indirect interactions (Callaway \& Walker 1997; Kunstler et al. 2006; Valladares et al. 2008; Maestre et al. 2009).

Since plants are sessile, the most intuitive way for approaching plant communities is through describing the spatial organization of the individuals (Watt 1947). Spatial structures can be used to relate the observed patterns to underlying ecological processes (Dale \& R. 1999) and if the appropriate spatial statistical tools are used, it is possible to infer causal hypotheses relating processes to patterns (Tirado \& Pugnaire 2003; McIntire \& Fajardo 2009). The main underlying processes that could be responsible for aggregation patterns are habitat heterogeneity, including effects on dispersal to favourable seed sinks, and facilitation, whereas regularity can result from intense competition for some limiting resource such as light and, in arid environments, water (Perry et al. 2006; Kunstler et al. 2007). However, the spatial patterns of individual plants in the field are usually complex, and the many and interacting underlying mechanisms can make the functional interpretation of these patterns cumbersome. Point pattern analyses and other spatial statistical tools have been frequently used to infer competitive and facilitative interactions among woody species (Tirado \& Pugnaire 2003; Escudero et al. 2005; Fajardo et al. 2008). Despite its importance, scaling up to the whole community of the numerous pairwise species interactions experiencing facilitation or competition has rarely been attempted. Some approaches have been conducted using indices of co-occurrence and adequate null models (Gotelli 2000), but their limitation at the multispecies level is well known. Popular point pattern analysis tools such as the bivariate or crossed K-functions (Lotwick \& Silverman 1982) have also been employed in this context but they have not produced a clear and direct interpretation in biological terms. Instead, we advocate the use of two neglected tools in plant ecology, analysis of segregation of species based on nearest-neighbour contingence tables (Dixon 2002) and the between types J-function (Van Lieshout $\&$ Baddeley 1999). Dixon's indices have a clear biological interpretation, as the tendency of a species (or species stage) to be associated with itself or with other species. This multispecies approach also has other practical advantages, such as the absence of conflicting results that sometimes occur with pair-wise tests. On the other hand, the between types J-function can be regarded as an index of dependence between types in a multispecies spatial pattern, so their results can be directly read within the context of biological interactions in a multispecies context. This approach, based on poorly used spatial statistics and the consideration of numerous stands covering the environmental range of the whole study area, can overcome the limitations of most studies that are either based on transplants, focused on spatial patterns in single plots, or limited to relatively simple pair-wise scenarios.

We have conducted an observational study exploring the spatial patterns of juvenile and adult individuals of four dominant tree species in a continental Mediterranean ecosystem, covering the whole range of environmental conditions in which these four species co-exist. Our study system is a continental Mediterranean forest-shrubland, dominated by junipers, evergreen and marcescent oaks and pines. These woody species co-exist but differ in abundance and demographic structure over a topographically complex landscape, and they give rise to four types of forest that are found over a wide climatic range. This model system is adequate to test the SGH in a multivariate context, in which several tree species co-exist with varying dominance along environmental gradients. Additionally, we hope to contribute to a better understanding of mechanisms controlling the co-existence of Mediterranean tree species through the explicit evaluation of spatial patterns at different levels of water availability. We hypothesized that: (i) recruitment is more frequent under the canopy due to milder abiotic conditions; (ii) the spatial association of juveniles with adults increases as water availability decreases according to SGH; and (iii) inter- and intraspecific interactions vary for different interacting species and for different microhabitats due to different tolerances to limiting or stressful factors for each species.

\section{Methods}

\section{Study area and species}

The study area is located in Alto Tajo Natural Park, in the central part of Spain (Guadalajara, Castilla-La Mancha, Spain, $\left.40^{\circ} 45^{\prime} 53^{\prime \prime} \mathrm{N}, 02^{\circ} 17^{\prime} 26^{\prime \prime} \mathrm{W}\right)$. The altitude varies from 706 to $1881 \mathrm{~m}$ a.s.l. The climate is continental Mediterranean, with hot and dry summers and cold winters, with a 
mean annual temperature of $10^{\circ} \mathrm{C}$ and a mean annual precipitation of $500 \mathrm{~mm}$. The maximum and minimum daily mean temperatures in Jan and Aug are 8.2 and $-3.5^{\circ} \mathrm{C}$, and 28.5 and $10.3{ }^{\circ} \mathrm{C}$, respectively (Agencia Estatal de Meteorología, Molina de Aragón weather station, 1971-2000). The soils are poorly developed and formed mainly from Cretaceous and Jurassic limestone.

We selected the following four types of forest, which are frequent and representative of Mediterranean ecosystems in continental areas: (i) juniper forests on high plateaus with Juniperus thurifera L. as the dominant species; (ii) pine forests of Pinus nigra J.F. Arnold ssp. salzmannii (Dunal) Franco; (iii) marcescent oak forests dominated by Quercus faginea Lam., which occupy more benign areas with deeper soil; and (iv) holm oak forests with Quercus ilex ssp. ballota (Desf) Samp. as the dominant species, usually on southfacing slopes. Although dominance of one species is always evident, the other three tree species also appear in all the forest stands examined. In addition, the understorey vegetation is dominated by the woody species Genista scorpius, Juniperus communis, Juniperus phoenicea, Juniperus oxycedrus, Buxus sempervirens, Arctostaphyllos uva-ursi, Rosmarinus officinalis, Thymus vulgaris and Lavandula officinalis.

\section{Sampling}

A total of 17 plots $(50 \times 2 \mathrm{~m})$ were set up perpendicular to the maximum slope. Four plots per forest type (holm oak forest, marcescent oak forest and Spanish juniper forest) and five plots of pine forests were randomly selected (Table S1; Fig. S1). Data were collected from Dec 2007 to Apr 2008. All individuals of Q. ilex ssp. ballota, Q. faginea, $P$. nigra ssp. salzmannit and J. thurifera were mapped at each plot. The height and DBH (diameter at breast height) of every individual were measured, as well as the microhabitat where they were located. We considered four types of microhabitat for each plot: (i) gaps; (ii) under the canopy of shrubs; (iii) under the combined canopy of shrubs and trees; and (iv) under trees. Individuals smaller or equal to $1 \mathrm{~m}$ in height were considered as juveniles (seedlings and saplings) and those greater than $1 \mathrm{~m}$ as adults.

\section{Environmental data}

Climate variables for each plot were obtained from the Digital Climatic Atlas of the Iberian Peninsula (ACDPI). The ACDPI is a set of digital climate maps of air temperature (minimum, mean and maximum), precipitation and solar radiation for the whole Iberian Peninsula, with a monthly and annual temporal resolution and a spatial resolution of $200 \mathrm{~m}$ (Ninyerola et al. 2005). Data for the climatic variables were obtained from meteorological stations (1951-1999 period), and data for geographic variables were elaborated from a 200-m resolution digital elevation model (DEM) of the Iberian Peninsula. Multiple regression coefficients were used to build the final maps, using digital layers for each geographic variable (altitude, latitude, continentality, solar radiation and geomorphology of the terrain) and applying GIS techniques (Ninyerola et al. 2005).

Using these data, we calculated the evapotranspiration of each plot according to the index proposed by Turc (1954): $\mathrm{ET}=(\mathrm{P} / \sqrt{ } 0.9)+\left(\mathrm{P}^{2} / \mathrm{L}^{2}\right)$, were ET is annual evapo-

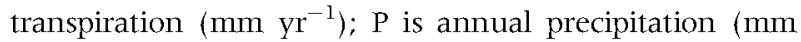
$\left.\mathrm{yr}^{-1}\right) ; \mathrm{L}=300+25 \mathrm{t}+0.05 \mathrm{t}^{3}$ and $\mathrm{t}$ is the mean annual temperature $\left({ }^{\circ} \mathrm{C}\right)$. The 17 study plots were classified in two groups (high and low water availability plots), considering water availability as annual precipitation minus annual evapotranspiration (Table S1). The classification of the plots was established according to K-means clustering performed with SPSS version 17.0 (SPSS Inc. Chicago, IL, US).

\section{Analysis of the frequency of juveniles in different microhabitats and water availability levels}

In order to test the frequency of individuals depending on their location, we built contingency tables (Table 1) summarizing the frequency of juveniles of the four species located in different microhabitats (in gaps, under the canopy of shrubs, under the combined canopy of shrubs and trees or only under trees). These contingency tables were built for the two groups of plots (high and low water availability plots - HWA plots and LWA plots, respectively) and analysed using log-linear models. Juveniles of $J$. thurifera were extremely rare in the HWA plots so they were

Table 1. Contingency table of the juvenile frequencies of Quercus ilex (Qlj), Quercus faginea (QFj), Pinus nigra (PNj) and Juniperus thurifera (JTj) in two plot types that differ in water availability level (WA level): high water availability plots (HWA) and low water availability plots (LWA). The number of individuals is expressed for different microhabitats: located in gaps (Gap); located under the canopy of shrubs (Shrubs); located under the combined canopy of shrubs and trees (Shrubs + Trees); located under trees (Trees).

\begin{tabular}{llrrrrr}
\hline \multirow{2}{*}{$\begin{array}{l}\text { Species } \\
\end{array}$} & $\begin{array}{l}\text { WA- } \\
\text { level }\end{array}$ & \multicolumn{2}{l}{ Microhabitat } & & & \\
\cline { 3 - 7 } & & Gap & Shrubs & Shrubs + Trees & Trees & Total \\
\hline Qjj & HWA & 122 & 24 & 18 & 216 & 380 \\
& LWA & 141 & 76 & 91 & 237 & 545 \\
QFj & HWA & 38 & 31 & 23 & 109 & 201 \\
& LWA & 24 & 32 & 51 & 50 & 157 \\
PNj & HWA & 57 & 16 & 7 & 262 & 342 \\
& LWA & 19 & 7 & 2 & 25 & 53 \\
JTj & HWA & 1 & 0 & 0 & 1 & 2 \\
& LWA & 27 & 28 & 7 & 39 & 101 \\
Total & & 429 & 214 & 199 & 939 & 1781 \\
\hline
\end{tabular}


excluded from this analysis. Log-linear models fit the expected cell counts to the marginal sums of the contingency table (see Agresti 1996 or Gotelli \& Ellison 2004). Deviations from expected frequencies were displayed and explored with mosaic plots (Friendly 1994), as recommended by Gotelli \& Ellison (2004). The mosaic plot is a graphical method for visualizing contingency tables and for building models to account for associations among model variables (Friendly 1994, 1999). All these statistical analyses were performed using the R software ( $\mathrm{R}$ Development Core Team 2009, Vienna, Austria).

\section{Analysis of nearest-neighbour contingency tables}

Spatial patterning was analysed using nearest-neighbour contingency table analysis of spatial segregation (Dixon 2002). This test of multi-way contingency tables described by Dixon (2002) and based on nearest-neighbour distances for multiple species offers a potential method to avoid performing a large number of pair-wise tests (Perry et al. 2006). Given the exact position of each tree in the plot, this measure of segregation compares the frequency of a given group of individuals to the frequency of all other groups (juveniles and adults of each species). The segregation index for a type of tree or a group in a multispecies spatial pattern is $\mathrm{S}_{\mathrm{i}}=\log \left[\left(\mathrm{N}_{i i} / \mathrm{N}_{i}-\mathrm{N}_{i i}\right) /\left(\mathrm{N}_{i}-1\right) /\left(\mathrm{N}-\mathrm{N}_{i}\right)\right]$, where $S_{i}$ is the segregation index for the type of tree $i, N_{i i}$ is the frequency of tree $i$ as a neighbour of tree $i, N_{i}$ is the number of trees $i$ and $\mathrm{N}$ is the total number of locations. Values of $S_{i}>0$ indicate that tree type $i$ is positively associated. The larger the value of $S_{i}$ the more extreme the association. Values of $S_{i}<0$ indicate that species $i$ is found as a nearest neighbour of itself less frequently than expected under random labelling. Values of $S_{i}$ close to 0 are consistent with random labelling of the neighbours of species $i$.

To analyse the association between two different types of points, Dixon (2002) also proposed the so-called 'pairwise segregation index' that can be constructed for the offdiagonal elements of the contingency table: $\mathrm{S}_{i j}=\log \left[\left(\mathrm{N}_{i j}\right)\right.$ $\left.\left.\mathrm{N}_{i}-\mathrm{N}_{i j}\right) / \mathrm{N}_{i} /\left(\mathrm{N}-\mathrm{N}_{j}-1\right)\right] . \mathrm{S}_{i j}$ is larger than 0 when $\mathrm{N}_{i j}$ (the frequency of neighbours of species $j$ around points of species $i$ ) is larger than expected under random labelling (hereafter 'positive association'), and less than 0 when $\mathrm{N}_{i j}$ is smaller than expected under random labelling (hereafter 'segregation'). As a species/neighbour-specific test, Dixon (2002) proposed the statistic $Z_{i j}=\left(N_{i j}-E_{i j}\right) / \sqrt{ } \operatorname{Var} N_{i j}$, where $j$ may be the same as $i$ and $\mathrm{EN}_{i j}$ is the expected count in the contingency table. It has an asymptotic normal distribution, with mean 0 and variance 1 ; its asymptotic $P$-value was obtained from numerical evaluation of the cumulative normal distribution. All these statistical analyses were conducted using the package ecespa (de la Cruz et al. 2008) in the R environment.
Associations among and within species and age classes at different distances

In order to analyse the association between pairs of species and age classes, we estimated the corresponding bivariate J-function (Van Lieshout \& Baddeley 1999): $\mathrm{J}_{i j}(\mathrm{t})=(1-\mathrm{G} i j(\mathrm{t})) /(1-\mathrm{F} j(\mathrm{t}))$, defined for all $\mathrm{t} \geq 0$ with $\mathrm{Fj}(\mathrm{t}) \neq 0$, where the function $\mathrm{G} i j(\mathrm{t})$ is the cumulative distribution of distances from a random tree of type $i$ to the nearest individual of type $j$, and $\mathrm{F} j(\mathrm{t})$ is the distribution function of the distance from a fixed tree in space to the nearest individual of type $j$ in the pattern. If the sub-process of type $i$ is independent of the subprocess of type $j$, then $J i j(\mathrm{t})=1$. Hence, deviations of the empirical estimate of Jij (t) from the value 1 may suggest dependence between types (Van Lieshout \& Baddeley 1999). Values of Jij $>1$ should be interpreted as 'negative association', while values smaller than 1 suggest 'positive association'. We chose this function as it can be calculated without correcting for the edge effect (see Baddeley et al. 2000). The null hypothesis chosen was random labeling, which is the same as that used in a previous analysis (see Diggle 1983). All these statistical analyses were conducted using the spatstat package (Baddeley \& Turner 2005) in the $R$ environment.

\section{Results}

Two groups of plots were classified with a clustering analysis (Table S1) based on environmental factors. These two groups are hereafter referred to as high water availability and low water availability plots (HWA plots and LWA plots, respectively). A total of 2066 individuals (1027 in HWA plots and 1039 in LWA plots), of which 1781 were juveniles (Table 1), were mapped in the 17 plots. The total number varied between 410 individuals of $Q$. ilex to 22 of $J$. thurifera in HWA plots and between 601 individuals of $Q$. ilex to 112 of $P$. nigra in LWA plots. The HWA plots significantly differed in all the climate variables compared with the LWA plots. The mean annual temperature $\left(t_{15}=\right.$ 2.39, $P=0.029)$, precipitation $\left(t_{15}=6.99, P<0.001\right)$, evapotranspiration $\left(t_{15}=6.01, P<0.001\right)$ and water availability $\left(t_{15}=7.06, P<0.001\right)$ were higher, while the radiation $\left(t_{15}=-2.76, P=0.014\right)$ was lower in the HWA plots than in LWA plots. The four types of forest (holm oak, marcescent oak, pine and juniper forests) were present in each of the two groups of plots. The species and age classes found, the density of juveniles and adults, and the basal area, topographic and climatic data for each plot are shown in Table S1.

The results showed that recruitment was more frequent under the canopy for some of the species but depended on 
the level of water availability. However, juveniles were not associated to conspecific adults. We observed a higher percentage of interactions, both positive and negative, in HWA plots than in LWA plots.

Frequency of juveniles in different microhabitats and water availability levels

There were significant differences in the frequencies of juveniles of the four species depending on microhabitat (Fig. 1) in both HWA and LWA plots (HWA plots: $\chi^{2}=77.50, d f=6, P<0.0001$; LWA plots: $\chi^{2}=57.16$, $d f=9, P<0.0001$ ). In the HWA plots, juveniles of $Q$. ilex were more frequent than expected by random in the gaps (Fig. la); however, the significance disappeared in plots with less water availability (Fig. lb). We found a higher frequency of juveniles of $Q$. faginea under shrubs and under the combined canopy of shrubs and trees in HWA plots, but no significant results were found in gaps (Fig. 1a). Yet, in LWA plots the frequency was lower in gaps and higher under the combined canopy of shrubs and trees. $P$. nigra juveniles were more frequent in HWA plots (Fig. la, b). In this case, juveniles were more frequently located under trees but not in gaps, nor under the canopy of shrubs or shrubs and trees together. The juveniles of $J$. thurifera were mostly present in the LWA plots, being rare in the HWA plots (Table 1). In the former plots (Fig. 1b), they were more frequently located under shrubs and less under the combined canopy of shrubs and trees.
Inter- and intra-specific associations between juveniles and adults

The results of the nearest-neighbour analyses contained more cases of significant spatial associations (Table 2) in the HWA plots $(42 \%)$ compared to the LWA plots ( $13 \%$ ), suggesting stronger spatial interactions between individuals when the climate conditions are milder. Twenty per cent of the HWA plots showed positive associations and $22 \%$ segregation, whereas in LWA plots only $6 \%$ showed positive associations and $7 \%$ segregation.

Our results provided strong evidence of a positive association among juveniles of $Q$. ilex (Table 2, Table S2), indicating a patchy distribution. Q. ilex juveniles were segregated from juveniles of $P$. nigra and of $Q$. faginea in the HWA plots, and with juveniles of $J$. thurifera in LWA plots (Table 2). We also found segregation between juveniles and adults of Q. ilex (HWA plots and LWA plots), as well as between juveniles of $Q$. ilex and adults of $J$. thurifera (LWA plots). The only positive association found for the juveniles of $Q$. ilex with other species was that with adults of $P$. nigra, which were positively associated only in one HWA plot. The juveniles of $Q$. faginea were positively associated in HWA plots but not with LWA plots (Table 2; Table S2). They were segregated from $P$. nigra juveniles (HWA plots and LWA plots), from $Q$. ilex juveniles (HWA plots) and from adults of $Q$. faginea in LWA plots. The juveniles of $Q$. faginea were positively associated with adults of $P$. nigra in almost all the HWA plots but in none of the LWA plots. $P$. nigra juveniles (Table 2; Table S2) were positively associated in $67 \%$ of the

$$
\text { (a) }
$$

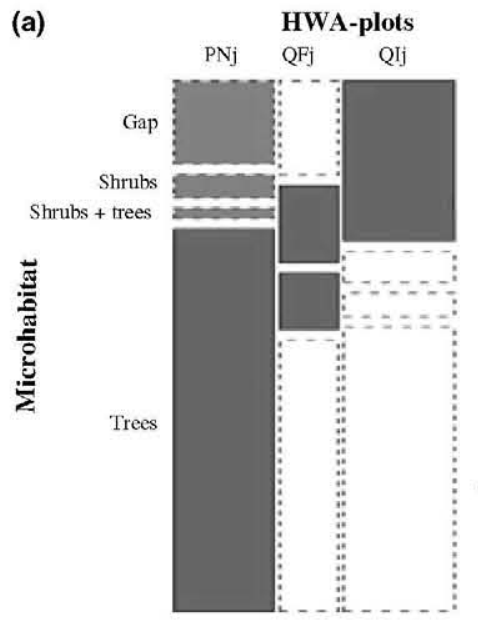

(b)

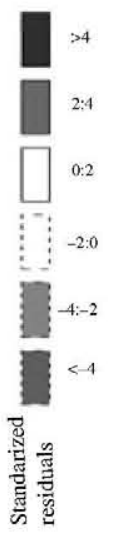

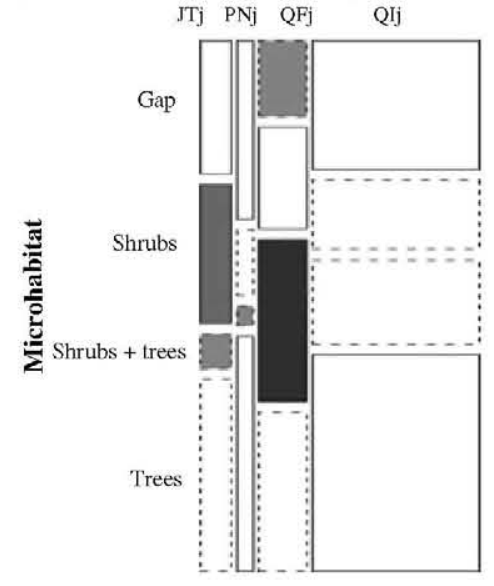

Fig. 1. Mosaic plots of the observed frequency of juveniles of Quercus ilex (Qlj), Quercus faginea (QFj), Pinus nigra (PNj) and Juniperus thurifera (JTj) in different microhabitats: in gaps (Gap), under the canopy of shrubs (Shrubs), the combined canopy of shrubs and trees (Shrubs+Trees) or only under trees (Trees), in (a) plots with high water availability (HWA plots) and (b) plots with low water availability (LWA plots). Juveniles of J. thurifera were not considered in HWA plots as only two individuals were found in these plots. The area of each rectangle is proportional to the cell frequency of the corresponding contingency table. Solid and broken lines indicate, respectively, positive and negative deviations from the expected frequencies. The shading of each rectangle is proportional to standardized residuals from the fitted model (values indicated in the legend). Light grey and black rectangles indicate significant deviations from the expected cell frequencies (at ca. $\alpha=0.05$ and $\alpha=0.0001$, respectively). 
Table 2. Summary of results for spatial patterns using nearest-neighbour contingency table analysis of spatial segregation (Dixon 2002). The numbers of plots that have each species combination, as well as percentages of significant positive and negative values of the segregation index are shown. The plots are classified according to water availability level (HWA plots: high water availability plots, and LWA plots: Iow water availability plots). 'Tree' is the focal tree and 'NN' is the nearest neighbour (QI, Quercus ilex; QF, Quercus faginea; PN, Pinus nigra; JT, Juniperus thurifera; followed by an -a for adults or by a -j for juveniles).

\begin{tabular}{|c|c|c|c|c|c|c|c|}
\hline \multirow[t]{2}{*}{ Tree } & \multirow[t]{2}{*}{ NN } & \multicolumn{3}{|l|}{ HWA plots } & \multicolumn{3}{|l|}{ LWA plots } \\
\hline & & $\begin{array}{l}\text { No. of plots } \\
\text { with species } \\
\text { combination }\end{array}$ & $\begin{array}{l}\% \text { of Sig. } \\
\text { positive } \\
\text { values }\end{array}$ & $\begin{array}{l}\% \text { of Sig. } \\
\text { negative } \\
\text { values }\end{array}$ & $\begin{array}{l}\text { No. of plots } \\
\text { with species } \\
\text { combination }\end{array}$ & $\begin{array}{l}\% \text { of Sig. } \\
\text { positive } \\
\text { values }\end{array}$ & $\begin{array}{l}\% \text { of Sig. } \\
\text { negative } \\
\text { values }\end{array}$ \\
\hline \multirow[t]{8}{*}{ Qlj } & Qlj & 5 & 100 & 0 & 9 & 44 & 0 \\
\hline & Qla & 3 & 0 & 33 & 4 & 0 & 50 \\
\hline & QFj & 5 & 0 & 60 & 5 & 0 & 0 \\
\hline & QFa & 2 & 0 & 0 & 2 & 0 & 0 \\
\hline & $\mathrm{PNj}$ & 3 & 0 & 67 & 3 & 0 & 0 \\
\hline & $\mathrm{PNa}$ & 4 & 25 & 0 & 4 & 0 & 0 \\
\hline & $\mathrm{JTj}$ & 0 & - & - & 4 & 0 & 25 \\
\hline & $\mathrm{JTa}$ & 0 & - & - & 4 & 0 & 25 \\
\hline \multirow[t]{8}{*}{ QFj } & Qlj & 5 & 0 & 60 & 5 & 0 & 0 \\
\hline & Qla & 3 & 0 & 0 & 1 & 0 & 0 \\
\hline & $\mathrm{QFj}$ & 6 & 33 & 0 & 6 & 0 & 0 \\
\hline & QFa & 2 & 0 & 0 & 3 & 0 & 33 \\
\hline & $\mathrm{PNj}$ & 3 & 0 & 33 & 3 & 0 & 33 \\
\hline & $\mathrm{PNa}$ & 4 & 75 & 0 & 5 & 0 & 0 \\
\hline & $\mathrm{ITj}$ & 1 & 0 & 0 & 1 & 0 & 0 \\
\hline & $\mathrm{JTa}$ & 1 & 0 & 0 & 1 & 0 & 0 \\
\hline \multirow[t]{8}{*}{$\mathrm{PNj}$} & Qlj & 3 & 0 & 33 & 3 & 0 & 0 \\
\hline & Qla & 2 & 0 & 0 & 1 & 0 & 0 \\
\hline & $\mathrm{QFj}$ & 3 & 0 & 67 & 3 & 0 & 33 \\
\hline & QFa & 1 & 0 & 0 & 2 & 0 & 0 \\
\hline & $\mathrm{PNj}$ & 3 & 67 & 0 & 3 & 33 & 0 \\
\hline & $\mathrm{PNa}$ & 3 & 0 & 33 & 3 & 0 & 0 \\
\hline & $\mathrm{JTj}$ & 1 & 0 & 0 & 1 & 0 & 0 \\
\hline & $\mathrm{JTa}$ & 1 & 0 & 0 & 1 & 0 & 0 \\
\hline \multirow[t]{8}{*}{$\mathrm{JTj}$} & Qlj & 0 & - & - & 4 & 0 & 0 \\
\hline & Qla & 0 & - & - & 2 & 0 & 0 \\
\hline & QFj & 1 & 0 & 0 & 1 & 0 & 0 \\
\hline & $\mathrm{QFa}$ & 0 & - & - & 1 & 0 & 0 \\
\hline & $\mathrm{PNj}$ & 0 & - & - & 0 & - & - \\
\hline & $\mathrm{PNa}$ & 0 & - & - & 1 & - & - \\
\hline & $\mathrm{JTj}$ & 0 & - & - & 4 & 25 & - \\
\hline & JTa & 1 & - & - & 5 & - & - \\
\hline
\end{tabular}

HWA plots and in $33 \%$ of the LWA plots. These individuals presented segregation from their conspecific adults and from Q. ilex juveniles only in HWA plots, and from Q. faginea juveniles $(67 \%$ of the HWA plots and $33 \%$ of the LWA plots). $J$. thurifera juveniles (Table 2; Table S2) were positively associated in $25 \%$ of the LWA plots.

\section{Juvenile associations at different spatial distances to other trees}

The results for every species, pair of species and age classes according to the J-functions were, in most cases, consistent with those found with the nearest-neighbour analysis (data not shown). For simplicity, we do not show all but only a summary of the bivariate J-function displays, with the percentage of cases in which positive and negative associations took place at different distances for juveniles of the four species in both types of water availability plots (Fig. 2). In general, we observed a higher percentage of negative than positive associations (Fig. 2). However, every species had its own spatial pattern that changed depending on water availability level and on the distance in some cases. The juveniles of $Q$. ilex in HWA plots (Fig. 2a) showed a higher percentage of negative associations at smaller distances, but positive associations exceeded this number at greater distances. Nevertheless, in LWA plots the negative associations were dominant at all distances for the juveniles of this species (Fig. 2b). 


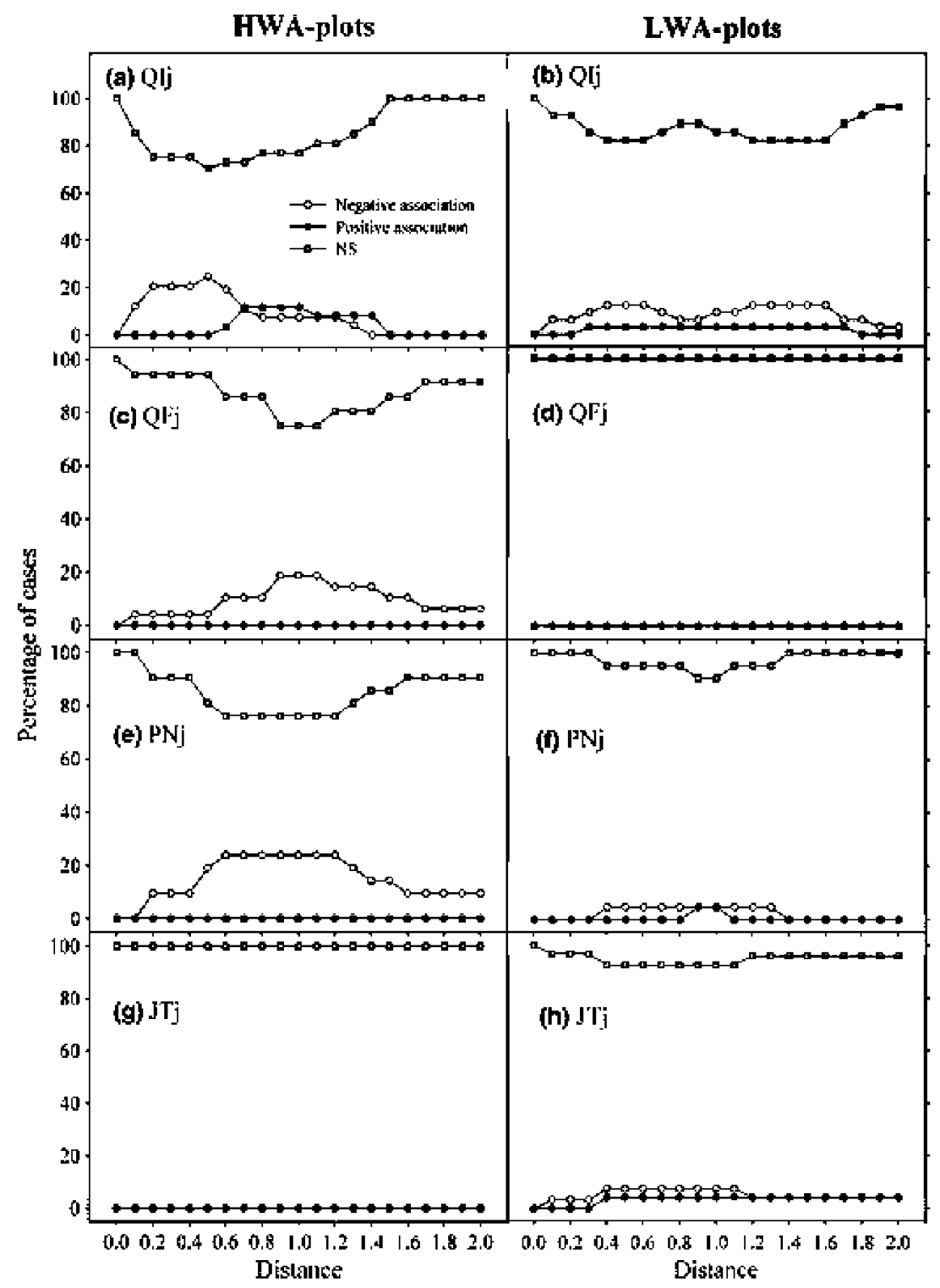

Fig. 2. Percentage of cases where estimates of the bivariate J-function computed among the mentioned focal species showed a significant positive association (black circles), significant negative association (white circles) and non-significant results (grey squares) at different scales (from 0 to $2 \mathrm{~m}$ ) in high water availability plots (HWA plots) and low water availability plots (LWA plots). (a,b) Quercus ilex juveniles (Qlj); (c,d) Quercus faginea juveniles (QFj); (e,f) Pinus nigra juveniles (PNj); (g,h) Juniperus thurifera juveniles (ITj).

Juveniles of $Q$. faginea and P. nigra presented similar patterns: there were only negative associations at all distances studied in HWA plots (Fig. 2c, e) but almost no significant results were found at any distance in the LWA plots (Fig. 2d, f). Juveniles of J. thurifera (Fig. 2g, h) showed almost no significant associations in either type of plot.

\section{Discussion}

By studying the spatial patterns of juveniles and adults in several plots and considering numerous pair-wise species, we have addressed the important knowledge gap at a multispecies level in the context of the stress-gradient hypothesis. More specifically, the results on spatial patterns, microsite preferences and species associations allow more detailed discussion of regeneration patterns.

Is recruitment associated with conspecific adult populations?

We observed that juveniles were not spatially associated with their conspecific adults; on the contrary, they were 
segregated in some plots, as in the case for $Q$. ilex and Q. faginea. It has previously been shown that acorns suffer extremely high predation rates under conspecific adults (Gómez 2004), as a result, seedling recruitment increases with distance from parent trees (Janzen 1970). In addition, oak canopy microhabitat is not appropriate for recruitment over the long term due to competition with adults (Gómez 2004; Valladares et al. 2008) or the existence of autoallelopathic substances ( $\mathrm{Li} \&$ Romane 1997) that inhibit germination. Juveniles of $P$. nigra recruited preferentially under the tree canopy, which is consistent with results obtained by Ordóñez et al. (2004), who found that the establishment of $P$. nigra was improved under cover levels higher than $25 \%$. However, when evaluating intra-specific associations, P. nigra juveniles did not show a positive association with conspecific adults or even showed segregation, suggesting that the higher frequency under trees may be a consequence of a higher density of the tree canopy and basal area in plots where pines are present (see Table S1), but not to a real species-specific association. J. thurifera juveniles did not show any spatial dependence with the conspecific adults, in contrast to the results of Montesinos et al. (2007), who showed a higher density of seedlings underneath female $J$. thurifera trees. These discrepancies may be related to the fact that in our sampling we did not discriminate between males and females, but also to the suggestion that the net effect of parents on recruitment can switch ontogenetically from facilitation to competition (Miriti 2006), finally resulting in a more attenuated positive association (Montesinos et al. 2007).

\section{Habitat preferences of juvenile trees}

The juveniles of $Q$. ilex were more frequent in gaps, while the other three species recruited preferentially under the canopy. The inter-specific associations varied depending on the interacting species and the level of water availability.

Similar to our results, Puerta-Piñero et al. (2006) found that the early establishment of oaks was benefited in gaps compared to under shrubs or under the canopy of Q. ilex due to the topsoil physicochemical properties. However, in our case, the frequency of $Q$. ilex juveniles was significantly higher in gaps only in HWA plots. If we move to more stressful conditions (LWA plots), the spatial pattern blurs: juveniles of $Q$. ilex were positively associated among them but there was no preferred specific location. These findings are consistent with those of Holmgren et al. (1997), who argued that in less dry conditions competition rather than facilitation is observed because the improvement of plant water relations under the canopy does not exceed the costs related to lower light levels. We suggest that whenever climate conditions are mild, Q. ilex tends to establish in gaps. In the gaps, acorns have a higher likelihood of escaping predation, germinate easily (Gómez 2004) and juveniles do not experience intense competition. Under drier conditions (LWA plots), the presence of juveniles of $Q$. ilex was not significantly higher in gaps than in HWA plots, but we did not find positive associations with other species. Instead, they were segregated not only from the conspecific adults but also from those of $J$. thurifera. This pattern suggests that the presence of neighbour trees can be negative when microclimate conditions are harsher (see Maestre et al. 2009).

The juveniles of the other three species did not show the same pattern as $Q$. ilex and recruited preferentially in other microhabitats rather than in gaps. The presence of $Q$. faginea was significantly lower in gaps of the driest plots, while non-significant results were found for those with higher water availability. Q. faginea juveniles recruited preferentially under the combined canopy of shrubs and trees, which led to the highest shading in our study system, independent of the water availability level. Therefore, Q. faginea seems to occupy low light environments more than the other species. These results agree with studies that show how this species benefits from its shade tolerance (Benayas et al. 2005; Gómez-Aparicio et al. 2006; Sánchez-Gómez et al. 2006; Maltez-Mouro et al. 2009). Q. faginea also experienced a positive association with adult pines in $75 \%$ of the HWA plots. This pattern can be attributed to postdispersal effects, as seed predators tend to spend less time looking for food under pines (Gómez 8 Hódar 2008). It is likely that pines provide safe sites for oak regeneration due to lower predation rates. However, the distribution pattern was not the same for the two oaks, indicating that the species have different niche requirements.

Pinus nigra juveniles were more frequent in HWA plots, mostly recruiting under the tree canopy, presumably due to the moister sites needed for germination. Pinyons are abundantly produced and wind-dispersed, as a consequence, seed rain is usually not a limiting factor for pine species (Jordano et al. 2004) but low soil moisture and high soil temperatures are likely to be the main factors controlling their recruitment (Barja et al. 2009).

Juniperus thurifera juveniles were only present in the most stressful plots (LWA plots), where they were mostly located under shrubs, but did not show significant interactions with any other species or age classes studied. This higher frequency under shrubs can be explained by the perch effect. The most relevant dispersers for juniper seeds are wintering thrushes -Turdus spp. - (Santos et al. 1999), which select shrubs such as Genista scorpius (very abundant in the study plots) to feed and deposit seeds via faeces underneath the shrubs. The higher density of seeds, together with less stressful environmental conditions under shrubs, increased nutrient content and herbivory amelioration are likely to improve germination, survival 
and growth (Verdú \& García-Fayos 2003; Gómez-Aparicio et al. 2004). However, there were fewer juveniles than expected under the combined canopy of both shrubs and trees, suggesting that high canopy density and the very low irradiance involved does not favour juvenile performance.

Analysis of the spatial distribution showed that the juveniles of each species were positively associated in at least one plot. This association was stronger among the juveniles of Q. ilex, followed by $P$. nigra, Q. faginea and $J$. thurifera. The most plausible explanation for these conspecific juvenile associations is the dispersal pattern of the seeds, combined with the species regeneration niche preference. We did not find any positive association between juveniles of the different species, but did find segregation from each other in many of the plots. As a result, it seems that none of these species share the same microhabitat or at least they present inhibition at very small scales. The competition between juveniles is usually not a main stress factor, so the inhibition found between these species may be due to distinct regeneration niche needs. We must take into account that our age class juveniles include both seedlings and saplings (individuals up to $1 \mathrm{~m}$ in height), so the different strategies might also be due to these two different life stages (Miriti 2006). Nonetheless, our results suggest that the four species have different physiological requirements that lead to recruitment to different niches when co-existing in the same community.

Testing the SGH: does the spatial dependence of juveniles increase with more stressful conditions?

It has been proposed that the net outcome of biotic interactions is the sum of co-occurring negative and positive interactions between neighbours, with facilitation generally becoming more important with increasing abiotic stress (Bertness \& Callaway 1994), and competition being more important under less stressful conditions (SGH). However, our results show that the spatial association of juveniles with adults or with shrubs does not increase under more stressful conditions (LWA plots compared to HWA plots). In fact, most of the associations, either positive or negative, were found in the plots with higher water availability. Thus, our results suggest that positive interactions do not increase in importance with increasing aridity under continental Mediterranean conditions. The few cases of associations in the most stressful conditions may be a consequence of the neutralization of advantages over disadvantages of the presence of neighbours. In fact, facilitation does not always increase in importance with abiotic stress (see Maestre et al. 2005). It is possible that the climate gradient explored here is not sufficiently contrasted to give a clear pattern concerning the interactions between species. We propose that our gradient goes from low (HWA plots) to intermediate (LWA plots) stress environments. In the former plots, the most competitive species are supposed to be dominant, while in intermediate stress environments both competitive and stress-tolerant strategies could co-occur as a result of beneficial processes of the dominant stress-tolerant species on the competitive ones, as suggested by Michalet et al. (2006). Our results do not show this pattern, as the dominant species are different in each plot, independently of the abiotic conditions. There are many contrasting results observed also in the literature that are mainly due to shifts in ontogeny (Miriti 2006), spatio-temporal scale (de la Cruz et al. 2008), complex responses when more than one stressor acts, different approaches (experimental vs. observational) and gradients considered (Dormann \& Brooker 2002; Maestre et al. 2005), often leading to difficulties in distinguishing between biotic and abiotic mechanisms structuring these communities. Hence, it seems clear that a full understanding of factors affecting these complex patterns requires further research.

\section{Conclusions}

Collectively, our results bring no support to the generality of the SGH in our study system, suggesting that positive interactions do not increase in importance with aridity. Regeneration patterns differ according to species composition, microhabitat characteristics and dispersal strategies. In general, juveniles do not recruit under conspecific adults. This study emphasizes the importance of considering a multispecies approach in several plots. Our approach overcomes many recognized limitations of most papers on facilitation since it involves a proper multidimensional comparison of specific patterns by combining poorly used spatial techniques and a high number of mapped plots.

\section{Acknowledgements}

We thank the Junta de Castilla-La Mancha, Director and Park rangers of the Alto Tajo Natural Park for permission to carry out the study in the park and for the information and facilities provided. Meteorological data for the reference station of Molina de Aragón were provided by the Spanish Agencia Estatal de Meteorología, and local data were obtained from ACDPI. We are very grateful to Teresa E. Gimeno for her valuable help in the experimental design and in fieldwork, to David L. Quiroga for his support in the field and to Jesús Martínez for GIS assistance. Suggestions of two anonymous referees helped to improve the manuscript. EG was supported by a FPI fellowship from the Spanish Ministry of Science and Technology. Funding was 
provided by the Spanish Ministry for Innovation and Science, with the grants Consolider Montes (CSD2008_ 00040) and VULGLO (CGL2010-22180-C03-03), and by a Community of Madrid grant REMEDINAL 2 (CM S2009/ $A M B-1783)$. We also acknowledge the collaborative effort within the GLOBIMED network.

\section{References}

Agresti, A. 1996. An introduction to categorical data analysis. John Wiley $\&$ Sons. New York, US.

Baddeley, A. \& Turner, R. 2005. Spatstat: an R package for analyzing spatial point patterns. Journal of Statistical Software 12: $1-42$.

Baddeley, A.J., Kerscher, M., Schladitz, K. \& Scott, B.T. 2000. Estimating the $\mathrm{I}$ function without edge correction. Statistica Neerlandica 54: 315-328.

Barja, A.D., Lucas-Borja, M.E., García, E.M., Serrano, F.R.L., Abellán, M.A., Morote, F.A.G. \& López, R.N. 2009. Influence of stand density and soil treatment on the Spanish Black Pine (Pinus nigra Am. ssp. salzmannii) regeneration in Spain. Investigación Agraria-Sistemas y Recursos Forestales 18: 167-180.

Benayas, J.M.R., Navarro, J., Espigares, T., Nicolau, J.M. \& Zavala, M.A. 2005. Effects of artificial shading and weed mowing in reforestation of Mediterranean abandoned cropland with contrasting Quercus species. Forest Ecology and Management 212: 302-314.

Bertness, M.D. \& Callaway, R. 1994. Positive interactions in communities. Trends in Ecology $\theta$ Evolution 9: 191-193.

Callaway, R.M. \& Walker, L.R. 1997. Competition and facilitation: a synthetic approach to interactions in plant communities. Ecology 78: 1958-1965.

Castroviejo, S. 1986-2011. Flora ibérica, plantas vasculares de la Peninsula ibérica e Islas Baleares. Real Jardín Botánico, CSIC Madrid, ES.

de la Cruz, M., Romao, R.L., Escudero, A. \& Maestre, F.T. 2008. Where do seedlings go? A spatio-temporal analysis of seedling mortality in a semi-arid gypsophyte. Ecography 31: $720-730$

Dale, M. \& R., T. 1999. Spatial pattern analysis in plant ecology. Cambridge University Press. Cambridge, UK.

Diggle, P.J. 1983. Statistical analysis of spatial point patterns. Academic Press, London, UK.

Dixon, P.M. 2002. Nearest-neighbor contingency table analysis of spatial segregation for several species. Ecoscience 9: 142-151.

Dormann, C.F. \& Brooker, R.W. 2002. Facilitation and competition in the high Arctic: the importance of the experimental approach. Acta Oecologica-International Journal of Ecology 23: 297-301.

Escudero, A., Romao, R.L., de la Cruz, M. \& Maestre, F.T. 2005. Spatial pattern and neighbour effects on Helianthemum squamatum seedlings in a Mediterranean gypsum community. Journal of Vegetation Science 16: 383-390.
Espelta, J.M., Riba, M. \& Retana, J. 1995. Patterns of seedling recruitment in west Mediterranean Quercus ilex forests influenced by canopy development. Journal of Vegetation Science 6: 465-472.

Fajardo, A., Quiroz, C.L. \& Cavieres, L.A. 2008. Spatial patterns in cushion-dominated plant communities of the high Andes of central Chile: how frequent are positive associations? Journal of Vegetation Science 19: 87-96.

Friendly, M. 1994. Mosaic displays for multiway contingency tables. Joumal of the American Statistical Association 89: $190-200$.

Friendly, M. 1999. Extending mosaic displays: marginal, conditional, and partial views of categorical data. Journal of Computational and Graphical Statistics 8: 373-395.

Gómez, J.M. 2004. Importance of microhabitat and acorn burial on Quercus ilex early recruitment: non-additive effects on multiple demographic processes. Plant Ecology 172: 287-297.

Gómez, J.M. \& Hódar, J.A. 2008. Wild boars (Sus scrofa) affect the recruitment rate and spatial distribution of holm oak (Quercus ilex). Forest Ecology and Management 256: 1384-1389.

Gómez-Aparicio, L., Zamora, R., Gómez, J.M., Hódar, J.A., Castro, J. \& Baraza, E. 2004. Applying plant facilitation to forest restoration: a meta-analysis of the use of shrubs as nurse plants. Ecological Applications 14: 1128-1138.

Gómez-Aparicio, L., Valladares, F. \& Zamora, R. 2006. Differential light responses of Mediterranean tree saplings: linking ecophysiology with regeneration niche in four co-occurring species. Tree Physiology 26: 947-958.

Gotelli, N.J. 2000. Null model analysis of species co-occurrence patterns. Ecology 81: 2606-2621.

Gotelli, N.J. \& Ellison, A.M. 2004. A primer of ecological statistics. Sinauer, Sunderland, MA, US.

Holmgren, M., Scheffer, M. \& Huston, M.A. 1997. The interplay of facilitation and competition in plant communities. Ecology 78: 1966-1975.

Janzen, D.H. 1970. Herbivores and number of tree species in tropical forests. American Naturalist 104: 501-528.

Jordano, P., Pulido, F., Arroyo, J., García-Castaño, J.L. \& GarcíaFayos, P. 2004. Procesos de limitación demográfica. In: Valladares, F. (ed.) Ecología del bosque mediterráneo en un mundo cambiante: 229-248, Ministerio de Medio Ambiente, Madrid, ES.

Kunstler, G., Curt, T., Bouchaud, M. \& Lepart, J. 2006. Indirect facilitation and competition in tree species colonization of sub-Mediterranean grasslands. Journal of Vegetation Science 17: $379-388$

Kunstler, G., Chadoeuf, J., Klein, E.K., Curt, T., Bouchaud, M. \& Lepart, J. 2007. Tree colonization of sub-Mediterranean grasslands: effects of dispersal limitation and shrub facilitation. Canadian Journal of Forest Research-Revue Canadienne de Recherche Forestiere 37: 103-115.

Li, J.Q. \& Romane, F.J. 1997. Effects of germination inhibition on the dynamics of Quercus ilex stands. Journal of Vegetation Science 8: 287-294. 
Lotwick, H.W. \& Silverman, B.W. 1982. Methods for analysing spatial processes of several types of points. Journal of the Royal Statistical Society Series B-Methodological 44: 406-413.

Maestre, F.T., Valladares, F. \& Reynolds, J.F. 2005. Is the change of plant-plant interactions with abiotic stress predictable? A meta-analysis of field results in arid environments. Journal of Ecology 93: 748-757.

Maestre, F.T., Callaway, R.M., Valladares, F. \& Lortie, C.J. 2009. Refining the stress-gradient hypothesis for competition and facilitation in plant communities. Journal of Ecology 97 : 199-205.

Maltez-Mouro, S., García, L.V. \& Freitas, H. 2009. Influence of forest structure and environmental variables on recruit survival and performance of two Mediterranean tree species (Quercus faginea L. and Q. suber Lam.). European Journal of Forest Research 128: 27-36.

McIntire, E.J.B. \& Fajardo, A. 2009. Beyond description: the active and effective way to infer processes from spatial patterns. Ecology 90: 46-56.

Michalet, R., Brooker, R.W., Cavieres, L.A., Kikvidze, Z., Lortie, C.J., Pugnaire, F.I., Valiente-Banuet, A. \& Callaway, R.M. 2006. Do biotic interactions shape both sides of the humpedback model of species richness in plant communities? Ecology Letters 9: 767-773.

Miriti, M.N. 2006. Ontogenetic shift from facilitation to competition in a desert shrub. Journal of Ecology 94: 973-979.

Montesinos, D., Verdú, M. \& García-Fayos, P. 2007. Moms are better nurses than dads: gender biased self-facilitation in a dioecious Juniperus tree. Journal of Vegetation Science 18: 271-280.

Ninyerola, M., Pons, X. \& Roure, J.M. 2005. Atlas Climático Digital de la Península Ibérica. Metodología y aplicaciones en bioclimatología y geobotánica. Universidad Autonoma de Barcelona, Bellaterra, Barcelona, ES.

Ordóñez, J.L., Franco, S. \& Retana, J. 2004. Limitation of the recruitment of Pinus nigra in a gradient of post-fire environmental conditions. Ecoscience 11: 296-304.

Perry, G.L.W., Miller, B.P. \& Enright, N.J. 2006. A comparison of methods for the statistical analysis of spatial point patterns in plant ecology. Plant Ecology 187: 59-82.

Puerta-Piñero, C., Gómez, J.M. \& Zamora, R. 2006. Speciesspecific effects on topsoil development affect Quercus ilex seedling performance. Acta Oecologica-International Journal of Ecology 29: 65-71.

Sánchez-Gómez, D., Zavala, M.A. \& Valladares, F. 2006. Seedling survival responses to irradiance are differentially influenced by low-water availability in four tree species of the Iberian cool temperate-Mediterranean ecotone. Acta Oecologica-International Journal of Ecology 30: 322-332.

Santos, T., Telleria, J.L. \& Virgós, E. 1999. Dispersal of Spanish juniper Juniperus thurifera by birds and mammals in a fragmented landscape. Ecography 22: 193-204.

Tirado, R. \& Pugnaire, F.I. 2003. Shrub spatial aggregation and consequences for reproductive success. Oecologia 136 : 296-301.
Turc, L. 1954. Le bilan d'eau des sols. Relation entre la precipitation, le évaporation et le écoulement. Annales Agronomiques 5: 491-595.

Valladares, F., Dobarro, I., Sánchez-Gómez, D. \& Pearcy, R.W. 2005. Photoinhibition and drought in Mediterranean woody saplings: scaling effects and interactions in sun and shade phenotypes. Journal of Experimental Botany 56: 483-494.

Valladares, F., Zaragoza-Castells, J., Sánchez-Gómez, D., Matesanz, S., Alonso, B., Portsmuth, A., Delgado, A. \& Atkin, O.K. 2008. Is shade beneficial for Mediterranean shrubs experiencing periods of extreme drought and latewinter frosts? Annals of Botany 102: 923-933.

Van Lieshout, M.N.M. \& Baddeley, A.J. 1999. Indices of dependence between types in multivariate point patterns. Scandinavian Joumal of Statistics 26: 511-532.

Verdú, M. \& García-Fayos, P. 2003. Frugivorous birds mediate sex-biased facilitation in a dioecious nurse plant. Joumal of Vegetation Science 14: 35-42.

Watt, A.S. 1947. Pattern and process in the plant community. Journal of Ecology 35: 1-22.

\section{Supporting Information}

Additional supporting information may be found in the online version of this article:

Table S1. Location of the study plots and their main characteristics ordered by the classification of water availability level according to a K-means cluster analysis. The species present at each plot are QI, Quercus ilex; QF, Quercus faginea; PN, Pinus nigra and JT, Juniperus thurifera. The species code is followed by either $-\mathrm{j}$ for juveniles or -a for adults.

Table S2. Significant results obtained by the nearest neighbor contingency table analysis of spatial segregation (Dixon 2002) at each plot and level of water availability (high-water-availability plots and low-water-availability plots -HWA and LWA, respectively-). 'Tree' means the focal tree and ' $\mathrm{NN}$ ' is the nearest neighbor (QI, Q. ilex; $\mathrm{QF}$, Quercus faginea; PN, Pinus nigra; JT, Juniperus thurifera; followed by -a for adults or by -j for juveniles). 'Obs' is the observed frequency and 'Exp' is the expected frequency in the contingency table. ' $S$ ' is the segregation index. When 'Tree' and ' $\mathrm{NN}$ ' are the same type of tree, it is $\mathrm{S} i$; values of $\mathrm{S} i>0$ indicate that these individuals are segregated (they are the nearest neighbors of themselves more often than expected from random labeling); $S i<0$ indicate the opposite and values of $S i$ close to 0 are consistent with random labeling of the neighbors of type $i$. When 'Tree' and 'NN' are different types of trees, it is $S i j$. Sij is larger than 0 when $\mathrm{N} i j$ (the frequency of neighbors of trees $j$ around trees $i$ ) is larger than expected under random labeling; $S i j<0$ indicates the opposite and values of $S i j$ close to 0 are consistent 
with random labeling. The signification of the index is tested indirectly with the statistic Zij (column Z) which $P$-value, based on the asymptotic normal distribution ( $P$-value.as) of the Z statistic.

Figure S1. Map of the Alto Tajo study area in Spain. Plot names (as in Table S1) are indicated according to the water-availability level: high water availability and low water availability (HWA and LWA, respectively).
Please note: Wiley-Blackwell are not responsible for the content or functionality of any supporting materials supplied by the authors. Any queries (other than missing material) should be directed to the corresponding author for the article. 